\title{
Simulation of Hetero-junction (GaInP/GaAs) Solar Cell Using AMPS-1D
}

\author{
Dennai Benmoussa ${ }^{1, *}$, M. Boukais ${ }^{2, \dagger}$, H. Benslimane ${ }^{1}$ \\ ${ }_{1}$ Physics Laboratory in Semiconductor Devices, University of Bechar, Algeria \\ 2 (URMER), University Abou Bakr Belkaid, B.P. 119, Tlemcen, Algeria
}

(Received 29 November 2015; revised manuscript received 03 March 2016; published online 15 March 2016)

\begin{abstract}
Photovoltaic conversion is the direct conversion of electromagnetic energy into electrical energy continuously. This electromagnetic energy is the most solar radiation. In this work we performed a computer modelling using AMPS 1D optimization of hetero-junction solar cells GaInP / GaAs configuration for p/n We studied the influence of the thickness the base layer in the cell offers on the open circuit voltage, the short circuit current and efficiency.
\end{abstract}

Keywords: Optimization, Photovoltaic cell, GaInP/GaAs AMPS-1D, Hetetro-junction.

PACS numbers: 73.50.Pz, 88.40.jr

\section{INTRODUCTION}

The research in the field of photovoltaics is primarily motivated by the improvement of energy conversion efficiency and the reduction of production cost. The cell performance can be improved by optimization of the physical parameters internal to provide both a shortcircuit, a shape factor and a high open circuit voltage. The simulation study of the solar cell is conducted using the program AMPS-1D reordered the three basic equations of semiconductor steady [1].

In recent years, the solar cells based on III-V materials have been widely used, especially for space applications, and because of their high efficiency and low degradation face to radiation in space [2].

However, a major problem was opposed to the development of solar cells, namely, that the surface recombination velocity. This is the reason for the return realized for the first solar cell was only about $10 \%$ [3].

The current supplied to the load is the difference between the photocurrent and the dark current.

The minimization of this current is desirable for improving cell performance. The dark current is determined by the combined effects of current transport mechanisms (injection, recombination)

In this vein, we proposed to treat photovoltaic cells based hetero-junction GaInP/GaAs [4].

In the present work, we used the optimization program called dimensional simulation (AMPS-D) analysis of microelectronic and photonic structures [5].

The Fig. 1 shows the schematic design of solar cells studied in this work. The objective of the simulation structure GaInP/GaAs hetero-junction solar cell was to verify the performance of this cell by varying the thickness of each layer base.

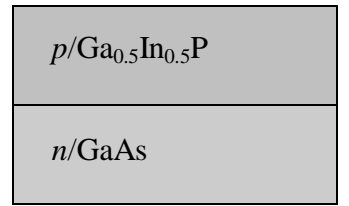

Fig. 1 - Structure employed for modeling
The performance of this slide solar primarily based on material parameters, optional parameters and electrical parameters of each layer in this structure.

\section{OPTIMAL DEVICE STRUCTURE}

The AMPS model was developed by the group Dr.S. J. Fonash the University of Pennsylvania and at set days later. Trapping and recombination in the AMPS model were determined using the formalism of Shockley-Read-Hall, taking into account beyond room temperature. In other words, the Taylor approximationSimmon's (0K) was not used. AMPS reflects the effective field strength variations caused by drift, diffusion, and affinity gap.

The boundary conditions were also general need of the electrostatic energy of the vacuum level (for the Poisson equation) and recombination rates of electron and hole contacts (TCO)/ $p$ and $n /$ metal (for both continuity equations). The AMPS model takes into account the storage and recombination of charge by the states of band tail states and dangling bonds. The final form dangling bonds are modeled by Gaussian distribution functions. Arch group in 1991 [6].

\section{MODELING AND SIMULATION}

In this study, a one-dimensional numerical analysis tool, AMPS-1D is used to create different types of solar cells and results. In AMPS-1D, two different layers are necessary for the modeling. More layers can be added as

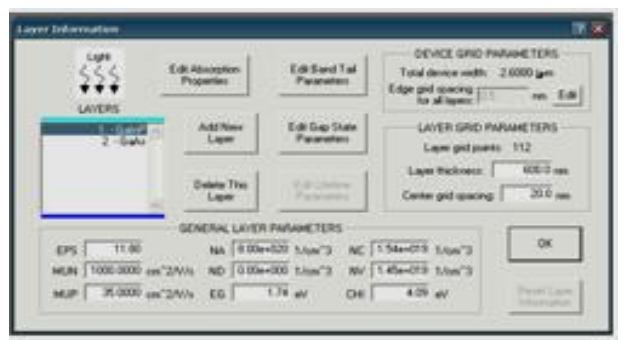

Fig. 2 - AMPS simulation front panel contains the device and layer grid parameters, and general layer parameters

\footnotetext{
*deennai_benmoussa@yahoo.com

$\dagger$ meri_232000@yahoo.fr
} 
long as the grid points do not exceed the limit, viz. 2000 -grid points. The two layers that are used in this modeling are the $p / \mathrm{Ga}_{0.5} \operatorname{In}_{0.5} \mathrm{P}$ émeteur and $n / \mathrm{GaAs}$ base). Table 1 show the description of the parameters used in the simulation and the basic parameter which are used in the study [5].

Table 1 - AMPS-1D solar cell

\begin{tabular}{|l|l|l|}
\hline \multicolumn{1}{|c|}{ Layers Parameters } & $p / \mathrm{Ga}_{0.5} \mathrm{In}_{0.5} \mathrm{P}$ & $n / \mathrm{GaAs}$ \\
\hline Thickness $(\mu \mathrm{m})$ & 2 & $0.5-5$ \\
\hline Dielectric constant, $\varepsilon$ & 11.80 & 12.90 \\
\hline Electron mobility $\mu_{n}\left(\mathrm{~cm}^{2} / \mathrm{Vs}\right)$ & 1000 & 8500 \\
\hline $\begin{array}{l}\text { Hole mobility } \mu_{p} \\
\left(\mathrm{~cm}^{2} / \mathrm{Vs}\right)\end{array}$ & 35 & 400 \\
\hline Carrier density, $n$ or $p\left(\mathrm{~cm}^{-3}\right)$ & $p: 1 \mathrm{E} 20$ & $n: 1 \mathrm{E} 16$ \\
\hline Optical band gap, $E_{g}(\mathrm{eV})$ & 1.74 & 1.42 \\
\hline Effective density, $N_{c}\left(\mathrm{~cm}^{-3}\right)$ & $1.54 \mathrm{E} 19$ & $4.77 \mathrm{E} 17$ \\
\hline Effective density, $N_{v}\left(\mathrm{~cm}^{-3}\right)$ & $1.45 \mathrm{E}+19$ & $9 \mathrm{E} 18$ \\
\hline Electron affinity, $\mathrm{X}(\mathrm{eV})$ & 4.09 & 4.07 \\
\hline
\end{tabular}

\section{RESULTS AND DISCUSSIONS}

\subsection{Influence of the Thickness of the Base}

On Fig. 3, 4 and 5 are shown the open circuit voltage, the short circuit current performance as a function of the thickness of the base layer.

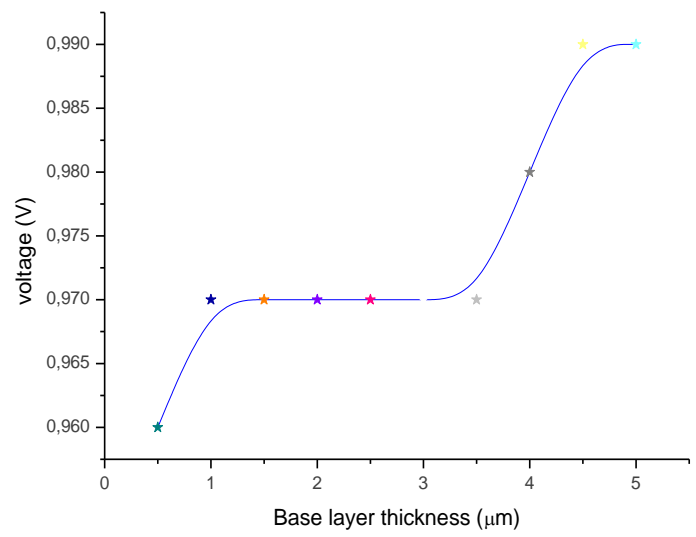

Fig. 3 - Variation Of open circuit voltage as à functions of the thickness the base layer

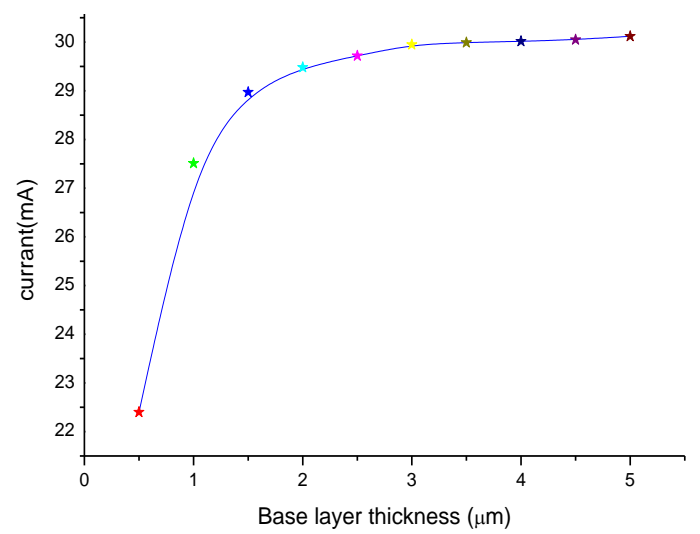

Fig. 4-Variation Of Short-circuit current as a functions of the thickness the base layer

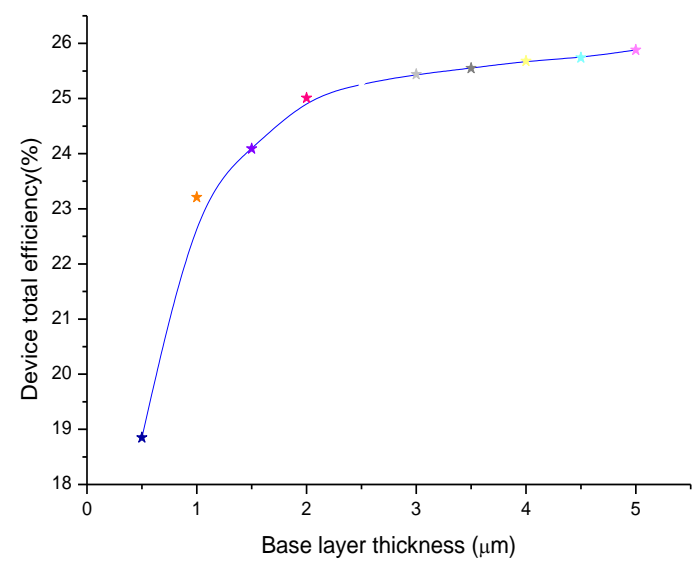

Fig. 5-Device total efficiency variation depending on the thickness the base layer

According to the simulation results, we noticed that when the substrate thickness increases, there is a growth in the short and open circuit slight increase in circuit voltage and therefore the yield increases.

This result is explained by the delay time passes the electron-hole pairs created in the emitter-base interface to the back contact.

\subsection{Optimization Results}

From the above results are obtained using the AMPS-1D software we can determine the solar cell which has the best performance while giving the thickness of each layer of the cell Table 2.

Table 2 - Thickness for each layer of solar cell optimize

\begin{tabular}{|c|c|c|}
\hline Layer & $p / \mathrm{Ga}_{0.5} \mathrm{In}_{0.5} \mathrm{P}$ & $n / \mathrm{GaAs}$ \\
\hline Thickness $(\mu \mathrm{m})$ & 2 & 5 \\
\hline
\end{tabular}

The current-voltage characteristics for the device hetero-junction GaInP/GaAs layers with the optimal concentrations are shown in Fig. 6, and the corresponding parameters $\mathrm{PV}\left(\mathrm{V}_{\mathrm{CO}}, \mathrm{J}_{\mathrm{SC}}, \mathrm{FF}\right.$ and efficiency) are summarized in Table 3.

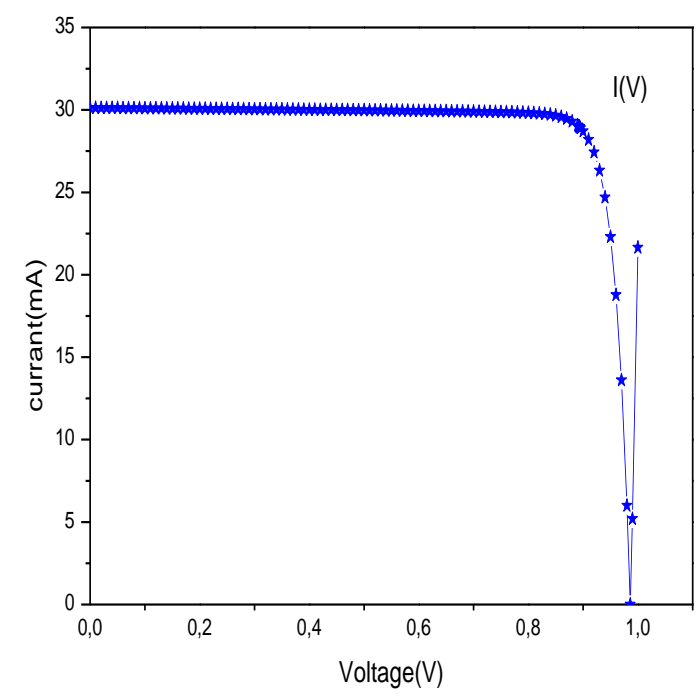

Fig. 6 - Current-voltage characteristics of solar cell optimized 
Table 3 - Photovoltaic solar cell hetero-junction parameters optimized

\begin{tabular}{|l|l|l|l|}
\hline$V_{C O}($ Volts $)$ & $J_{S C}\left(\mathrm{~mA} / \mathrm{cm}^{2}\right)$ & $F F(\%)$ & $\eta(\%)$ \\
\hline 1.10 & 32.74 & 0.89 & 32.07 \\
\hline
\end{tabular}

\section{CONCLUSIONS}

Whatever the structure of a solar cell, an optimization of its parameters is necessary to have a good performance. Usually among the parameters to be optimized are the thickness of the cell and the optical confinement. Optimal parameter values depend, of course, the structure of the solar cell, the quality of the material, the surface recombination velocity (front and

\section{REFERENCES}

1. E. Van Kerschaver, G. Beaucarne, Prog. Photovolt. Res. Apl. 14, 107 (2006).

2. M. Orgeret, Les piles Solaires, le Composant et ses Applications (Edition Masson: 1985).

3. H.J. Hove land, J.M. Woodall, J. Electrochem. Soc. 120, 1246 (1973).

4. H. Ben Slimane, A. Helmaoui, Revue des Energies Re- rear), etc. The optimization of the solar cell therefore comprises the study of the influence of these parameters on the performance to obtain a structure leading to maximum efficiency.

The results show that the thickness of the solar cell is an important parameter for the absorption of photons.

\section{AKNOWLEDGEMENTS}

We would like to acknowledge the use of AMPS-1D program that was developed by Dr. Fonash's group at Pennsylvania State University (PSU).

nouvelables 11 No 2, 259 (2008).

5. M.J. Ludowise, W.T. Dietze, R. Boettcher, N. Kaminar, Appl. Phys. Lett. 43, 468 (1983).

6. H. Zhu, A.K. Kalkan, J. Hou, S.J. Fonash, Proc. National Center for Photovoltaics (NCPV) 15th Program Review Meeting, 462 (1999). 